\title{
Editorial
}

\section{JIDC and Latin America}

\author{
Alfonso J. Rodríguez-Morales and Salvatore Rubino \\ Journal of Infection in Developing Countries
}

Key words: research; Latin America; infectious diseases

J Infect Dev Ctries 2012; 6(9):652-653.

(Received 13 September 2012 - Accepted 14 September 2012)

Copyright (C) 2012 Rodríguez-Morales and Rubino. This is an open-access article distributed under the Creative Commons Attribution License, which permits unrestricted use, distribution, and reproduction in any medium, provided the original work is properly cited.

This year marked the fifth anniversary of the publication of the Journal of Infection in Developing Countries. JIDC was launched strongly supported by scientists from developing countries. The objective of this enthusiastic journal has been to allow researchers in developing countries access to a high-quality international journal, not just to read but more importantly, to publish research for others to read. JIDC has evolved to be a high-quality journal, not just publishing anything concerning infectious disease in developing countries, but keeping in mind the need to maintain quality, accepting articles of high quality and trying to improve the quality of the research submitted (using the mentoring system).

Over the past five years, researchers and authors worldwide, particularly those from developing countries, have benefited from this international forum. Indexed in the major relevant databases such as PubMed, Medline, Science Citation Index and Scopus, among many others, the journal has become an important vehicle for the dissemination of scientific findings, progress and research in the field of infectious diseases.

Latin America is one of the many developing regions of the world that has been affected by the inception of this journal. A very diverse region sharing predominantly two languages and cultural roots from Spain and Portugal, this area compromises 19 countries over 21 million square kilometers with a population of around 572 million of persons. Scientific research in the field of infectious diseases has been growing steadily in this region during the last two decades [1], and JIDC has had the opportunity to present the findings of committed researchers from 14 of those countries: Argentina, Bolivia, Brazil, Chile, Colombia, Cuba, El Salvador, Guatemala, Mexico, Panama, Paraguay, Peru, Uruguay and Venezuela (Figure 1). From an available total number of 664 articles indexed in Medline, 93 (14\%) were published in JIDC, with the majority of the publications coming from Brazil (21, 23\%), Argentina (18, 19\%), Mexico $(17,18 \%)$, and Venezuela $(10,11 \%)$. Authors from Brazil, Argentina and Colombia have published clinical trials and systematic reviews in JIDC, among the best contributions in the generation of scientific evidence in the field.

Importantly, JIDC's commitment to publish articles from authors in developing countries has allowed us to report research on infectious diseases and pathogens that might be seen as too "regional" for consideration in other journals but are endemic or highly relevant in their specific regions, such as Chagas Diseases (American trypanosomiasis), Plasmodium vivax malaria, leishmaniasis, dengue, tungiasis, HTLV-1, Vibrio parahaemolyticus, among many others.

Interest in publishing in JIDC has been continuously growing in Latin America. For example, in 2007, one article was published from Argentina, two in 2008, and we are now up to five from Argentina in 2012. Now that JIDC has an important impact factor (1.2), we expect to attract more papers from the whole community of researchers in infectious diseases as well from highly remarkable Latin American researchers.

Participation from Latin America will keep continuously growing, particularly in infectious tropical diseases, where investigators from the region are becoming more and more recognized for research 
Figure 1. Contributions to JIDC from Latin American countries (2007-2012)

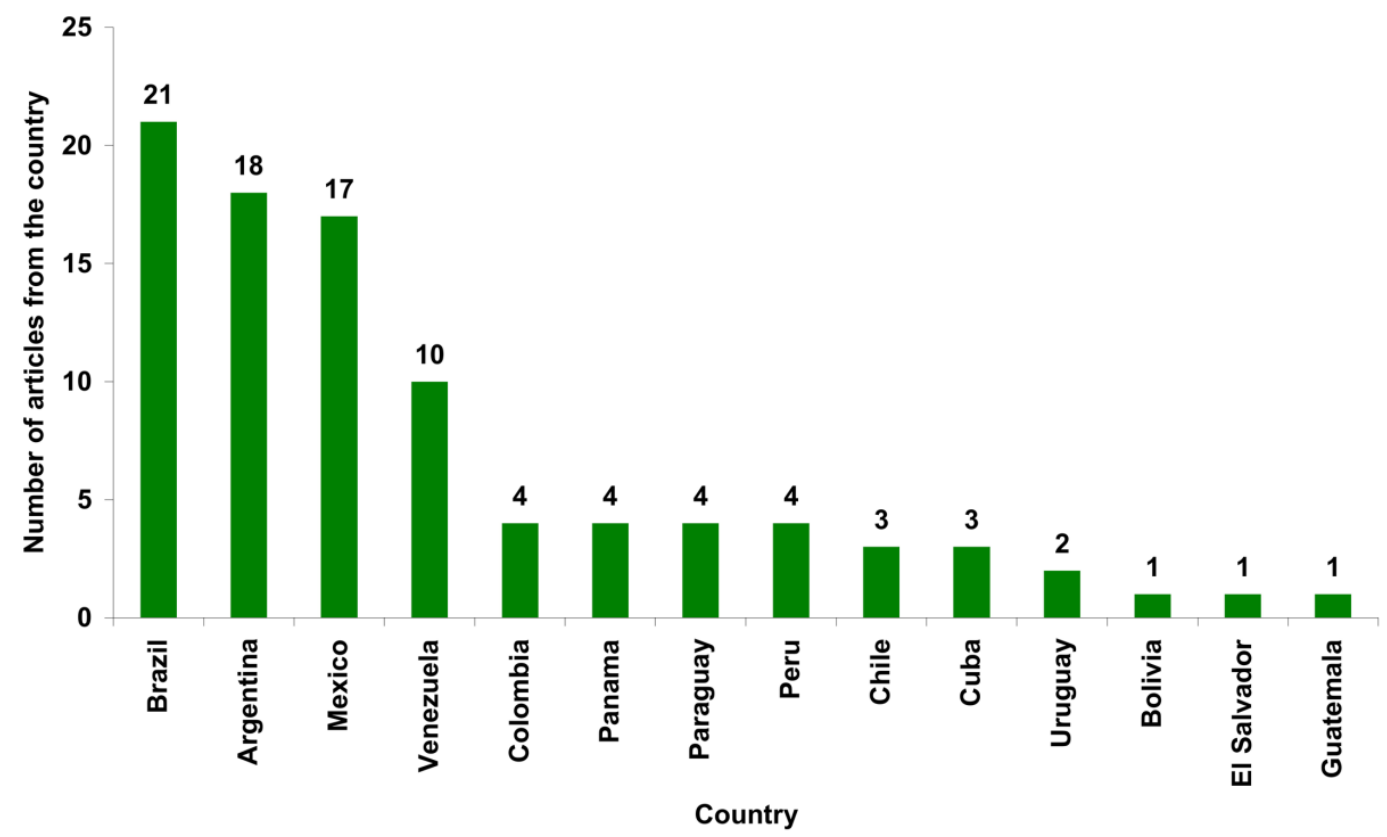

excellence in this field. Their achievements will be reflected in events such as the XVIII International Congress for Tropical Medicine and Malaria, the XLVIII Congress of the Brazilian Society of Tropical Medicine, and the upcoming 3rd Latin American Congress of Travel Medicine, to be held in Rio de Janeiro, Brazil, on September 23-27, 2012 [2]. This major scientific congress is held regularly every four years and this is the third time the conference has been organized in Latin America (VII was held in Brazil in 1963 and XV in Colombia in 2000). It is likely that many papers from Latin America and other developing regions will be initially presented there and later submitted to JIDC.

As always, we look forward to welcoming research manuscripts from this growing region and investigators worldwide.

\section{References}

1. Rodríguez-Morales AJ and Mayta-Tristan P (2009) Preliminary bibliometric evaluation of scientific publications produced in Latin America in the field of tropical and infectious diseases using SciELO. J Infect Dev Ctries 3: 247249.

2. Rodriguez-Morales AJ and Zuckerman JN (2012) Extending across continents: Travel Medicine and Latin America. Travel Med Infect Dis 10: 55-56.

\section{Corresponding authors}

Alfonso J. Rodríguez-Morales

Email: arodriguez@jidc.org

Salvatore Rubino

Email: srubino@jidc.org

Conflict of interests: No conflict of interests is declared. 